\title{
EXPERIMENTALISMO E LIBERDADE NO SUPLEMENTO LITERÁRIO DO MINAS GERA/S (1966-1975)
}

Viviane Monteiro Maroca*

RESUMO: Este trabalho apresenta os contos publicados pelos Novos no Suplemento Literário do Minas Gerais entre os anos 1966 e 1975, enfocando o conceito de conto que ali circulou e relacionando alguns aspectos da teoria e da prática ficcional dos Novos. A hipótese que aqui se apresenta é que o discurso crítico de experimentalismo e liberdade se articulava com a produção ficcional de alguns dos contistas do Suplemento Literário do Minas Gerais (SLMG). Os autores selecionados para se pensar a questão da liberdade foram Luiz Vilela, Humberto Werneck, Sérgio Sant'Anna e Jaime Prado Gouvêa. Vale ressaltar que todos os contos publicados por esses autores eram inéditos até a ocasião.

PALAVRAS-CHAVE: Suplemento Literário do Minas Gerais: Contos Brasileiros (1960-1970); História e Crítica Literatura e História; experimentalismo.

\author{
* viviane.maroca@gmail.com \\ Mestre em Teoria da Literatura. Atualmente, cursa o \\ Doutorado em Teoria da Literatura e Literatura Comparada \\ pelo Programa de Estudos Literários da FALE - UFMG.
}

ABSTRACT: This work presents short stories published by Os Novos in the literary section of the newspaper Diário Oficial de Minas Gerais between 1966 and 1975, and confronts the concept of short story addressed by this generation of writers with short stories published in that section, bearing in mind the theory and practice of Os Novos. The hypothesis hereby presented is that the discourse of freedom and experimentalism was articulated with the fiction of those writers. The authors chosen to represent the corpus were Luiz Vilela, Humberto Werneck, Sérgio Sant'Anna and Jaime Prado Gouvêa, and all the short stories were unpublished by then.

KEYWORDS: Suplemento Literário do Minas Gerais, Brazilian short-stories (1960-1970), History and Criticism, Literature and History; experimentalism. 
O Suplemento Literário do Minas Gerais, concebido por Murilo Rubião, também seu primeiro secretário, foi lançado em 1966 e vinha encartado semanalmente ao diário oficial do Estado. Ali, publicaram-se contos, poemas (traduções de autores consagrados), crítica de arte, cinema e literatura. O Suplemento dava voz à crítica acadêmica, assim como acolhia os novos escritores que surgiam a partir de meados da década de 1960 e que desejavam publicar sua literatura e sua crítica. A partir de dois números especiais de 1968, dedicados a estes escritores, organizados pela poetisa e crítica Laís Corrêa de Araújo, passou-se a chamar aquela nascente geração de escritores de Os novos.

O conto foi o gênero literário sobre o qual mais se refletiu ali. Em cada número do SLMG, havia um conto novo e é enorme a lista de contistas que estavam ligados a este jornal. Alguns atingiram reconhecimento nacional, outros permaneceram no anonimato. Para listar alguns, destaco os nomes de Duílio Gomes, Jaime Prado Gouvêa, Wander Piroli, Lucienne Samôr, Sérgio Sant'Anna, Luis Gonzaga Vieira, Humberto Werneck, Luiz Vilela. Em meus levantamentos, estes foram os contistas novos que publicaram mais frequentemente no jornal e sobre os quais mais se falou ali. Somam-se, ainda, àqueles nomes, aproximadamente outros 185 , que publicaram poucas ou apenas uma vez no semanário, dado que reitera a acessibilidade que aquele jornal provia aos novos escritores. Sem mencionar os poetas que lá colaboraram ou os romancistas sobre os quais se falaram em resenhas de seus livros ou ensaios sobre suas obras.

Se o Suplemento nasceu como uma página cuja função era amenizar "a prosa burocrática"1 do diário oficial do estado, este intuito foi superado, criando-se um dos mais importantes e longevos suplementos literários do Brasil. Sem dúvida, por contar com a colaboração de escritores, críticos e intelectuais de importância, como Murilo Rubião, Affonso Ávila, Laís Corrêa de Araújo, Fábio Lucas, Maria Luísa Ramos e Rui Mourão, para nomear poucos desses. Murilo, considerado um guru pelos novos, os recebeu, escalou alguns deles para redação do jornal e fez com que sua literatura fosse publicada. Relembrando que a prosa de Murilo pouco se assemelhou à dos novos, notando-se que este contista nunca intencionou fundar uma escola ou criar seguidores de sua estética, reafirmo o caráter acolhedor do Suplemento, que abrigava múltiplas vozes, aspecto já notado por outros críticos. Assim, os ensaios encontrados no jornal - redigidos pelos novos, como Vieira e Sant'Anna - conduziram-me a perceber, através do discurso iconoclasta dos novos, a formação de um grupo, que visava romper com uma literatura pregressa e com um modelo de conto tradicional, firmando-se como uma geração; o discurso crítico do novos do Suplemento é de ruptura.
1. WERNECK. $O$ desatino da rapaziada, p. 178.

\begin{tabular}{|c|c|c|c|c|c|}
\hline EM TESE & BELO HORIZONTE & v. 19 & N. 3 & SET.-DEZ. 2013 & MAROCA. Experimentalismo e liberdade no Suplemento Literário [...] \\
\hline
\end{tabular}

\section{Ensino e teoria}


2. SANT'ANNA. Os novos de Minas: o problema da participação, p. 3.
Torna-se claro, a partir do discurso dos novos, que eles tinham consciência do papel de mediador do Suplemento, não sendo ele apenas um espaço comum que utilizavam para suas publicações, mas o lugar a partir do qual se configuraria uma nova geração:

A principal importância dos recentes números do SLMG, dedicados aos escritores novos de Minas, é, acreditamos, servir como o primeiro ponto de referência para e sobre uma geração que, longe de se prestar a juízos definitivos, dá ainda seus primeiros passos e se definirá a partir do que for realizando e sendo. Um instante captado de uma coisa em movimento, portanto. ${ }^{2}$

Já naquele primeiro instante, 1968, embora Sérgio Sant'Anna não soubesse precisamente definir o que os configurava, a si e a seus contemporâneos, como uma geração, notava ali a ocorrência de um fenômeno que envolvia aqueles jovens escritores por suas similitudes. Em 1997, com um olhar dessa vez retrospectivo, o contista Duílio Gomes percebe que o Suplemento

teve, entre outros méritos, o de aglutinar em sua redação uma nascente geração literária. Eram prosadores e poetas mineiros que, capitaneados por Rubião - na verdade, uma espécie de "guru" para aqueles jovens - começavam a publicar seus contos, poemas e textos de pura vanguarda no semanário. A gênese dessa criação coletiva, segundo o próprio Murilo Rubião, trazia instrumental e virtudes suficientes para promover uma ruptura com a geração anterior e estabelecer-se com legitimidade coerente. O que, para cada nova geração, significa estética nova. ${ }^{3}$

Em fins do século XIX, como aponta Assis Brasil ${ }^{4}$, o conto ganhou novas feições no âmbito da literatura brasileira, feito realizado por Machado de Assis. O crítico ainda observa que os escritores Afonso Arinos, Hugo de Carvalho Ramos e Lima Barreto também trouxeram contribuições ao gênero, e que "nos anos próximos a 1922 e nos primeiros subseqüentes, quando surgiram escritores como Adelino Magalhães, Alcântara Machado, João Alphonsus, Mário de Andrade, o gênero passou a ter certa autonomia criativa." 5 Após esse período, os contistas detinham-se, sobretudo, no anedótico, deixando um pequeno vão na evolução do gênero conto na literatura nacional. Contudo, "quando a história curta no Brasil se arrastava moribunda", Rosa e Clarice Lispector. Note-se que o conto se revitaliza a partir do fim da década de 1960, o que poderá ser comprovado pelo trabalho dos contistas do Suplemento Literário do Minas Gerais, mas este processo teve seus primeiros frutos, assim como assinala Assis Brasil, em fins da década de 40 e princípio de 50, quando alguns autores, além de Clarice e Rosa, Samuel Rawet, Breno Accioly, Dalton Trevisan, José J. Veiga, Ivan Ângelo, Rubem Fonseca lançaram suas
3. GOMES. Arquivo. Suplemento, p. 12

4. BRASIL. A Nova Literatura III: O conto, p.21.

5. Ibidem, p.48

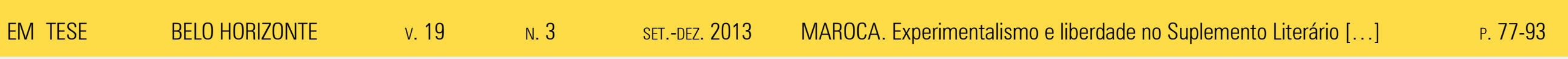

\section{Ensino e teoria}


7. BOSI. História concisa da Literatura Brasileira, p. 386-387.

8. Ibidem, p. 386-387

9. Ibidem, p. 386-387. primeiras obras. Deve-se observar que nem todos eram exclusivamente contistas. O precoce Murilo Rubião também compunha este corpo. Na época áurea do romance regionalista, Rubião lança, em 1947, O ex-mágico. O autor atinha-se à confecção de narrativas curtas (o conto foi o único gênero ao qual o autor se dedicou ao longo de sua vida), além de ter trazido a narrativa de cunho fantástico ao horizonte da literatura brasileira, enquanto os grandes escritores nacionais empenhavam-se no feitio de retratos da realidade.

Alfredo Bosi aponta alguns dos traços que moldavam a ficção brasileira pós-1930 até o início da década de1960; no período entre 1930 e 1945/507, o autor indica o "Nordeste decadente", "as agruras da classe média no começo da fase urbanizadora" e "os conflitos internos da burguesia entre provinciana e cosmopolita" como as principais condições sócio-econômicas do Brasil, da década de 40, que dão forma à prosa de ficção. $\mathrm{O}$ crítico aponta que, a partir do Governo JK, já no período de 1950/55, a ideologia do desenvolvimentismo e do nacionalismo - que deixara de estar ligado ao pensamento de direita e é assumido pela "bandeira esquerdizante" - tornava-se o "fulcro do pensamento social”. Tinha-se, então, uma ficção de cunho regionalista ora "envolta nas tramas do ensaísmo social or permeada pela inconstância da lírica moderna - marcada por um fluxo que não se sabe só objetivo ou subjetivo"9 - acabando por culminar no romance introspectivo.
Já ao tratar dos escritores que se situam temporalmente na década de 60 do século XX, Bosi, nas considerações finais da mesma obra referida acima, História Concisa da Literatura Brasileira, previne que:

O historiador do século XXI que, ajudado pela perspectiva do tempo, puder ver com mais clareza as linhas-de-força que atravessam a ficção brasileira neste fim de milênio, talvez divise, como dado recorrente, certo estilo de narrar brutal se não intencionalmente brutalista, que difere do ideal de escrita mediado pelo comentário psicológico e pelo gosto das pausas reflexivas ainda vigente na "idade de ouro do romance brasileiro" entre os anos 30 e $60{ }^{10}$

O período histórico em que ocorrem estas modificações no campo da literatura é bastante delicado no que toca a política brasileira. Como aponta Flora Süssekind, em Literatura e Vida Literária, o golpe militar forneceu, inicialmente, apoio às manifestações culturais até 1968 , permitindo o engajamento nas artes, contanto que fossem "cortados seus possíveis laços com as camadas populares" ${ }^{11}$.

A respeito da literatura brasileira da década de 1960, Heloísa Buarque de Hollanda, em Impressões de viagem: CPC, vanguarda e desbunde: 1960/70, aponta que aquela foi uma época de debate "em torno do engajamento e da eficácia revolucionária da palavra poética" ${ }^{12}$, embora já se anunciassem
10. BOSI. História Concisa da Literatura Brasileira, p. 434-435.

11. SÜSSEKIND. Literatura e vida literária, p.22. Cf. COELHO, Diversidade critica e literária Minas Gerais (1966-73): iupto Minas Gerais (1966-73): ruptura de fronteiras, que também contextualiza o periodo histórico em questão com base na obra de Flora Süssekind.

12. HOLLANDA. Impressões de viagem: $C P C$, vanguarda e desbunde: 1960/70, p.15.

EM TESE BELO HORIZONTE $\quad$ v. $19 \quad$ N. $3 \quad$ SET.-DEz. $2013 \quad$ MAROCA. Experimentalismo e liberdade no Suplemento Literário [...] $\quad$ P. 77-93

\section{Ensino e teoria}


13. Ibidem, p.15.

14. Ibidem. p.17.

15. Ibidem, p.18.

16. Ibidem, p.18.

17. Ibidem, p.18.

18. Ibidem, p.19.

19. Ibidem, p.38. 20. Ibidem, p.38. algumas cisões "que incomodavam o tom sério e empenhado da 'produção popular revolucionária"'13 mas que só se apresentariam de maneira mais contundente após meados da década. Segundo a autora, o CPC dividia a postura dos artistas e intelectuais brasileiros de então em três: o conformismo no qual o artista alienado "estaria perdido em seu transviamento ideológico"14, o inconformismo, que o levava a fazer parte "daquele grupo de intelectuais movido por um 'vago sentimento de repulsa pelos padrões dominantes', por uma 'revolta dispersiva' e uma 'insatisfação inconseqüente"'15, mas sem adotar uma postura de adesão ou cumplicidade com "'os propósitos ostensivos dos inimigos do povo" " ${ }^{16}$, e a atitude revolucionária conseqüente, que "o CPC toma como sua: os membros do CPC optaram por ser povo, por ser parte integrante do povo, destacamento do seu exército no front cultural." "17

Problemas surgem quanto a esta concepção de "arte como instrumento de tomada de poder"18, que recusa qualquer manifestação artística que não seja empenhada em agir para um bem maior, por uma coletividade, que não vislumbre o operário como "a expressão mais moderna das sociedades industriais" ${ }^{19}$, já que "dele depende, e a ele está ligado o que pode haver de novo, o que pode haver de transformação"20.

A vanguarda concretista se rende, em um momento, a esta temática, tentando "justificar a pertinência de sua produção: 'O operário quer um poema racional, que lhe ensine a pensar como a máquina lhe ensina - e se gosta de rosas há de preferi-las reais, que as alegóricas já estão felizmente mortas em sua sensibilidade positiva." ${ }^{21}$ Assim, a autora afirma que:

Caía então a vanguarda na armadilha desenvolvimentista: a crença de que o país estaria ultrapassando o subdesenvolvimento para ingressar numa nova era de país desenvolvido. A modernização que de fato ocorria - mas para adequar a economia brasileira a uma nova etapa de dependência, marcada pela integração ao capital monopolista - era mal avaliada e mitificada. Nesse sentido, podemos dizer que a revolução imaginada pela vanguarda concretista era uma ficção. Seu equívoco a colocava numa posição colonizada e colonizadora. Suas declarações de intenção revolucionária caíam por terra em sua práxis cultural que se mostrava completamente integrada às relações de produção do sistema, cujo movimento de modernização e integração a uma nova etapa de dependência o concretismo acompanhava. O poema concreto lançava mão da linguagem do sistema mas mostrava-se incapaz de tocá-lo criticamente. ${ }^{22}$

Nesse sentido, novas manifestações artísticas surgem, opondo-se às manifestações engajadas de princípios da década de 1960. Hollanda ressalta que "a contracultura, o desbunde, o rock, o underground, as drogas, e mesmo a psicanálise passam a incentivar uma recusa acentuada pelo projeto do período anterior. É nessa época que um progressivo desinteresse pela
21. HOLLANDA. Impressões de viagem: $C P C$, vanguarda e desbunde: $1960 / 70$, p. 38.

EM TESE BELO HORIZONTE $\quad$ v. $19 \quad$ N. $3 \quad$ SET.-DEz. $2013 \quad$ MAROCA. Experimentalismo e liberdade no Suplemento Literário [...] $\quad$ P. 77-93

\section{Ensino e teoria}


23. lbidem, p.65.

24. Ibidem, p.65.

25. Ibidem, p.66. política começa a se delinear"23, e novos temas como a "liberdade”, a "desrepressão", a "procura de 'autenticidade"24 vão, pouco a pouco, delineando as bases da criação artística:

Ser marxista, no fim de algum tempo, passa a ser visto como um enigma, principalmente se vem acompanhado de alguma preocupação de participação política mais efetiva, constituin do-se em demonstração insofismável de 'caretice'. É nessa linha que aparece uma noção fundamental - não existe a possibilidade de uma revolução ou transformações sociais sem que haja uma revolução ou transformação individuais. ${ }^{25}$

Após 1968, com a instauração do AI-5 que, dentre outras coisas, proibia manifestações de natureza política e vetava o habeas corpus àqueles que praticaram crimes contra a segurança nacional, viu-se o poder dos militares levado ao extremo em detrimento das liberdades individuais e coletiva. Curiosamente, o Suplemento Literário do Minas Gerais, que tinha o corpo editorial composto por intelectuais de esquer$\mathrm{da}$, surgiu durante a ditadura militar brasileira e resistiu aos seus anos mais ferrenhos. Os anos de 1966 a 1975 foram de grande efervescência cultural para o semanário; a partir daí, o Suplemento passou a sofrer censura e teve um secretário designado pelo governo Aureliano Chaves.

Assis Brasil, crítico que tratou da produção ficcional de alguns contistas da época em questão, aponta uma mudança que se deu na estrutura do conto da referida geração. Antes de mostrar qual foi ela, introduz os traços básicos da estrutura tradicional do conto, que era, sobretudo, presa à "movimentação episódica, assim como a novela e o romance"26, e tinha enfoque na intriga (ou "plot", como prefere dizer o autor), que "prenderia" a atenção do leitor até o final da narrativa. Sendo assim, as peculiaridades de cada autor se evidenciariam através de suas marcas estilísticas e da trama que "embora conservasse a sua espinha dorsal (o ponto de vista), variava de interesse e de cor de escritor para escritor, e de interesse na elucidação dos diversos episódios desenrolados." ${ }^{27}$

Segundo o crítico, a primeira mudança efetuada no gênero diria respeito à forma, quando o enfoque no episódio passa a ser substituído pelo "flagrante", libertando-se da "velha narrativa onisciente e sendo o primeiro gênero, na prosa de ficção, que abandonou os antecedentes orais do relato" ${ }^{28}$. Ao artista já não cabia mais desenvolver um enredo curto, que o possibilitasse apenas a elaboração de uma narrativa curta, mas desenvolver a forma, "que exigia um tratamento, um equilíbrio, uma unidade" 29 . Ainda, a respeito desta mudança do desenvolvimento do enredo pelo flagrante, o crítico afirma que:

Difícil, é verdade, talvez impossível, assinalar precisamente a mudança do 'plot' na narrativa curta, ou a sua total abolição do gênero, ou ainda a sua integração total ao conto. Talvez tenha
26. BRASIL. A Nova Literatura III: O conto, p.21.

27. Ibidem, p.21

28. Ibidem, p. 25

29. Ibidem, 1975, p.28

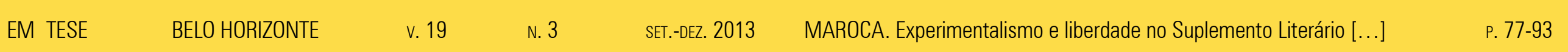

\section{Ensino e teoria}


31. Cf. BRASIL. A Nova Literatura III: O conto. surgido um 'novo valor' dentro do próprio 'plot' para o conto de flagrante, ou o conto sem episódio, sem ação externa, ou sem enredo algum." ${ }^{30}$

Ao pensar o conto dos autores desta geração, que teve como precursores os escritores Breno Accioly, Jones Rocha e Murilo Rubião, que abandonaram o realismo e os enredos concatenados em detrimento de uma "visão de mistério e tempo interior humanos," Assis Brasil ${ }^{31}$ evidencia uma nova revolução no caráter do conto, que poderia, a partir daquele momento, trazer em sua narrativa apenas uma atmosfera ou situação, fundidas às impressões do autor.

Porém, os autores tidos como de fundamental importância para os novos, que publicaram anteriormente a eles, e com cujas obras deveriam romper, não são apenas esses, mas, sobretudo Clarice Lispector e Guimarães Rosa:

Nós somos uma geração de ficcionistas que cresceu sob o sig no de Guimarães Rosa e Clarice Lispector. Mas o caso é que os monstros sagrados, à parte o seu exemplo liberador, são ciclos que começam e acabam em si mesmos. Não há como continuá-los. Por isso a vantagem de ler Oswald de Andrade é que ele abre caminhos e possibilidades que não se esgotam em seus livros.

Para quem escrevia contos, também foi bom quando começaram a aparecer os livros de Rubem Fonseca, propondo novas aberturas. Rubem Fonseca (assim como Cortázar e Donald Barthelme) me parece um autor exatamente nessas condições: na fronteira entre o conto e aquilo que não o é mais. E esta é a fronteira onde nos encontramos. ${ }^{32}$

Não que se ignorasse a importância de sua obra; para Sérgio Sant'Anna, "no Brasil, em Guimarães Rosa, há uma síntese totalizadora perfeita entre o 'que é dito' e o 'como é dito'." ${ }^{3}$ Embora se reconhecesse que a importância de escritores como Rosa, o repúdio ao pensamento dos escritores regionalistas era sobremaneira forte, que ia para além da representação do espaço geográfico, alcançando o plano da linguagem. Em um ensaio de 1973, Sérgio Sant'Anna, para o Suplemento Literário do Minas Gerais assegura:

Literatura mineira? Não existe isso não. O que existe, se existe, é literatura. Estamos caminhando para o fim da região e do regionalismo. A comunicação de massas - sem juízo de valor está gerando uma linguagem nacional unificada e até mesmo com características internacionais. Expressões como 'ó xente', 'uai' e 'trem bão' vão desaparecer irremediavelmente do vocabulário das pessoas. Ainda bem. ${ }^{34}$

Os novos defendiam a abordagem de temas universais como se não fosse possível que estes se realizassem em meio a representações espaciais locais. Apesar do que aponta Sant'Anna, a localidade está presente em contos dos novos escritores do
32. SANT'ANNA. Depoimento: 0 conto não existe, p.7.

33. Ibidem, p. 7.

34. Ibidem, 1973a, p.6

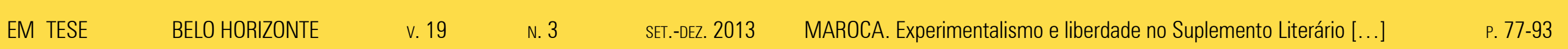

\section{Ensino e teoria}


35. VILELA. O suicida.

36. VIEIRA. $O$ conto atual II, p.10.
SLMG, como se pode verificar em $O$ suicida ${ }^{35}$ de Luiz Vilela. Nesse texto há a presença de expressões coloquiais usadas em Minas como: "Trem feio, sô" ou "Acho que eu sofro um trem".

A experiência da censura e da repressão referida, naquele mesmo suplemento literário, como uma situação beco sem saída ${ }^{36}$, torna-se uma das condicionantes da criação ficcional naquele contexto. Ao tratar da forma do conto em uma série do fim dos anos 60, Luis Gonzaga Vieira sustenta, exaustivamente, que o mais importante, para os escritores que surgiam naquele contexto, seria que não se criassem regras de composição; o conto deveria ser livre e nem mesmo sua extensão deveria ser delimitada. O crítico prega uma espécie de existencialismo estético, único subterfúgio encontrado para romper com imposições formais e resistir contra o autoritarismo nas manifestações artísticas. A negligência à forma e a exaltação do Existencialismo como vertente filosófica, como uma volta ao indivíduo, guiaria, em grande medida, a confecção do objeto estético na década de 1960. Luis Gonzaga Vieira, em abril de 1970, Situação do conto em Minas, aponta que:

os escritores mineiros sentem a literatura principalmente como uma pressão individual e social, ou, se quiserem, dentro de uma acentuada inquietação existencial. Os ficcionistas mineiros, de que falo, são estes de 1970 que têm mais ou menos entre 25 e 30 anos de idade. $\mathrm{O}$ ano de 1970 serve como refe- rência, pois pensamos aqui numa geração que, sem grandes rigores, apareceu a partir de 1965 com a publicação da revista de contos Estória. Pensamos naturalmente que essa geração não apareceu assim de repente, mas surgiu exatamente por um efeito de uma inquietação anterior, uma inquietação que no começo seria apenas literária e que depois evoluiu para uma visão mais complexa. Quero dizer que hoje os problemas existenciais são levados em conta com a mesma intensidade da coisa literária. Digo ainda que esses escritores mineiros saíram de certo ostracismo para uma participação muito consciente e aguda da realidade.[...]A pergunta que então surge é a seguinte: como posso comunicar alguma coisa se o mundo me sufoca? É uma pergunta que não impede a criação literária, mas que aumenta a inquietação e a pressão, a vontade maior de testemunhar esse sufocamento. É como se tivéssemos de criar alguma coisa, mas sendo ameaçados de muito perto. A literatura já não é sentida como coisa pacífica, mas como uma atividade altamente ameaçada e ameaçadora. ${ }^{37}$

Alfredo Bosi, em $O$ conto brasileiro contemporâneo, ao pensar o conto dos anos 60/70, atribui à sua extensão a possibilidade de condensar e potenciar "todas as possibilidades de ficção" e de travar uma "luta mais intensa com as técnicas de invenção, de sintaxe compositiva, de elocução: daí ficarem transpostas depressa as fronteiras que no conto separam o narrativo do lírico, o narrativo do dramático." 38 O autor
37. VIEIRA. Situação do Conto em Minas (trechos de um ensaio), p. 9.

38. BOSI. O conto brasileiro contemporâneo, p.7.

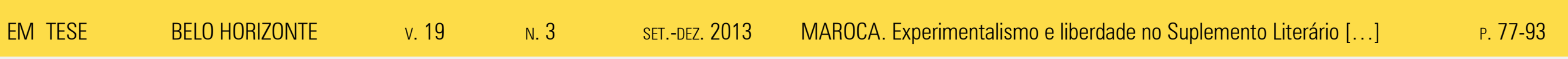

\section{Ensino e teoria}


39. Ibidem, p.7.

40. Os contos que caminham nesse sentido são: Lavouras, Feliciade, Subir na vida, Triste, Lembrança, de Luiz Vilela, O condenado, Quarta-fera, Febre aos trinta andar, de Humberto Werneck: Os campos dourados, O Segundo campos dourados, O Segundo degrau, Chuva, Circulos, A noite grande, de Jaime Prado Gouvêa Fábrica e $O$ Arquiteto, de Sérgio Sant'Anna. salienta algumas das possíveis facetas que a narrativa curta poderia adquirir a partir dali:

O conto cumpre a seu modo o destino da ficção contemporânea. Posto entre as exigências da narração realista, os apelos da fantasia e as seduções do jogo verbal, ele tem assumido formas de surpreendente variedade. Ora é o quase-documento folclórico, ora a quase-crônica da vida urbana, ora o quase-drama do cotidiano burguês, ora o quase-poema do imaginário às soltas, ora, enfim, grafia brilhante e preciosa voltada às festas da linguagem. ${ }^{39}$

Embora Bosi note o caráter heterogêneo do conto das décadas de 1960 e 70, apontando para a impossibilidade de encaixá-lo "num quadro fixo de gêneros", argumento que é possível aproximar tematicamente o trabalho de alguns desses contistas, em especial, de Luiz Vilela, Humberto Werneck, Jaime Prado Gouvêa e Sérgio Sant'Anna, a partir de sua publicação no SLMG. Os quatro autores publicaram no suplemento contos que traziam como o eixo temático a representação de um sujeito ora solitário, ora atormentado, ora tolhido ${ }^{40}$, em consonância com a hipótese de Luis Gonzaga Vieira exposta acima. Grande parte dos contos em questão traz uma temática que diz respeito à solidão do homem, agora em contato com o espaço urbano, podendo ser o sujeito representado com um olhar mais objetivo, em sua relação com o espaço urbano. Dentro desse espaço, as personagens tornam-se coisas ou têm sua individualidade suprimida. $\mathrm{E}$ preciso notar que quanto às características do conto tradicional que deveriam ser abandonadas - segundo o próprio discurso dos novos, em seus ensaios críticos encontrados no SLMG - nesta fase ainda não se veem mudanças tão radicais no que toca a questão do experimentalismo estético.

Dentro de um conjunto de contos bastante heterogêneos, há alguns que se destacam, sobretudo, por seu cunho experimentalista. Foram Sérgio Sant'Anna e Jaime Prado Gouvêa os autores que se arriscaram a experimentos mais extravagantes no âmbito do semanário. Os ensaios que Sant'Anna remeteu ao Suplemento propunham um trabalho de ruptura, e sua ficção não poderia ser diferente. Em $O$ conto não existe, o autor sugere que se faça uma literatura que rompa com a tradição narrativa preexistente, dizendo:

Estes críticos que ainda produzem teorizações do tipo 'o conto é isso', 'o conto é aquilo', não estão com nada. O conto não existe.

[...] Tenho trabalhado naquilo que se pode chamar de 'textos de ficção', alguns já publicados: um ensaio poético -macabro sobre o automóvel; Uma 'obra-aberta' que deve ser escrita pelo leitor; um roteiro para um filme (ou vídeo-tape) cultural; um texto de epígrafes e dedicatórias; o cardápio de um restaurante giratório-microbiótico; o guia turístico de uma cidade gigantesca e fantasmagórica; um texto-projeto de criação coletiva etc.

EM TESE $\quad$ BELO HORIZONTE $\quad$ v. $19 \quad$ N. $3 \quad$ SET.-Dez. $2013 \quad$ MAROCA. Experimentalismo e liberdade no Suplemento Literário [...] $\quad$ P. 77-93

\section{Ensino e teoria}


41. SANT'ANNA. Depoimento: o conto não existe, p.6.

42. Conto publicado no número 301 do SLMG, jun. 1972. Cf. SANT'ANNA, $O$ automóvel.
[...]Para quem escrevia contos, também foi bom quando começaram a aparecer os livros de Rubem Fonseca, propondo novas aberturas. Rubem Fonseca (assim como Cortázar e também o americano Donald Barthelme) me parece um autor exatamente nestas condições: na fronteira entre o conto e aquilo que não o é mais. E esta é a fronteira onde nos encontramos. ${ }^{41}$

Alguns destes textos, embora tenham sido publicados como contos no SLMG, recebem outras designações de seu autor. É o caso de $O$ Automóvel (ensaio poético) ${ }^{42}$, que já anuncia, em seu título, um experimento no campo dos gêneros textuais. Após extrair do dicionário Caldas Aulette o verbete automóvel, compõe o texto com definições da Enciclopédia Larousse para as partes importantes de um carro. A seguir, o autor discursa sobre os inconvenientes do automóvel, a começar pelos engarrafamentos nas cidades grandes, o elevado número de acidentes em estradas, que acusam uma grande quantidade de mortos e feridos nos dias de lazer, que superam, em números, os mortos em guerra. $\mathrm{Na}$ outra parte do texto, que se expande, ocupando toda a página do jornal, encontram-se sete parágrafos/estrofes, nos quais foram abolidos todos os verbos e conectivos, restando apenas substantivos que designam os possíveis restos encontrados à beira da estrada, todos eles concluídos com a palavra sangue. Deve-se notar que a publicação no jornal permite experiências com o espaço da folha, e as ilustrações, também enviadas por outros colaboradores do SLMG, possibilitam uma leitura suplementar ${ }^{43}$ dos contos, ganho raramente possível nos livros, nos quais, quase sempre, ${ }^{44}$ se suprimiram as ilustrações posteriormente à publicação no jornal.

Outro texto que não se prende à definição de gênero é Obra $a_{b e r t a}{ }^{45}$, não sendo possível conceituá-lo como um gênero, nem mesmo ficção, poesia ou ensaio. É uma proposta de criação de texto que oferece um espaço para que o leitor se torne um escritor. Seguindo as instruções, o leitor preencherá as linhas em branco que sucedem ao texto e, "dentro do moderno conceito de obra aberta", se libertará "de toda e qualquer tirania por parte do autor, tornando-se ele próprio o autor" ${ }^{\text {" }}$. $\mathrm{O}$ autor sugere aos leitores que seus conselhos acadêmicos podem ser ignorados: "SÓ QUANDO VOCÊ DEIXAR DE OUVIR CONSELHOS RETRÓGRADOS É QUE ESTARÁ PENETRANDO NO TERRITÓRIO PERIGOSO E ESCORREGADIO DA CRIAÇÃO”. Ao fim, surge a proposta de temas dos quais o leitor poderia se valer para criar sua própria narrativa: "um fim de semana na praia", "uma viagem ao estrangeiro", "um sonho erótico", "carta à mamãe", "minha namorada", "meu cachorro", "um assassinato". Com propostas bastante irônicas, este texto possui, também, uma atitude crítica diante do academicismo e das teorizações. Estando à espera que suas linhas vazias sejam escritas, não se saberá se o leitor compactuará com o autor, cumprindo sua "proposta
43. Suplemento, aqui, no sentido derridiano de "adição, um significante disponível que se acrescenta para substituir e suprir uma falta do lado do significado e fornecer o excesso do que é preciso." SANTIAGO, Glossário de Derrida, p.88.

44. SANT'ANNA. Uma visita, domingo à tarde, no museu. 0 conto traz a ilustração original do SLMG

45. SANT'ANNA. Obra aberta. Conto publicado no número 316 do SLMG, set. 1972.

46. Ibidem.

EM TESE BELO HORIZONTE $\quad$ v. $19 \quad$ N. $3 \quad$ SET.-DEz. $2013 \quad$ MAROCA. Experimentalismo e liberdade no Suplemento Literário [...] $\quad$ P. 77-93

\section{Ensino e teoria}


47. SANT'ANNA, Roteiro para um filme - vídeo-tape cultural. Conto publicado no número 327 do SLMG, dez. 1972. Cf. SANT'ANNA, 1972c.

48. SANT'ANNA, Roteiro Turístico de Goddamn City. Conto publicado no número 351 do SLMG,

maio 1973. C. SANTANNA, posteriore texto foi recolhido posteriormente como um capitulo de Confissóes de Ralfo.

49. SANT'ANNA, Roteiro para um filme - vídeo-tape cultural.

50. SANT'ANNA, Três pequenas estórias. Conto publicado no número 288 do SLMG, mar. 1972. de narrativa”. Em Obra aberta, a literatura volta-se para si mesma e para o questionamento de alguns aspectos da teoria e da crítica literária, enfatizando essa oscilação entre ficção ou ensaio, não se fixando a nenhuma, contudo, problematizando, também, a questão da recepção.

$\mathrm{O}$ autor publica dois textos aos quais chama de roteiros no SLMG: Roteiro para um filme - vídeo-tape cultural $^{47}$ e Roteiro Turístico de Goddamn City ${ }^{48}$. O primeiro deles, carregado de autorreferencialidade e ironia, é o relato de um dia na vida do escritor Célio Sartana em quinze cenas. Em Roteiro Turístico de Goddamn City, não há personagens ou enredo, restringindo-se apenas à descrição espacial. Os dois textos dialogam. No primeiro texto, há uma menção ao roteiro turístico, sendo sua autoria atribuída a Célio Sartana que o descreve como um "poema épico [...] inspirado numa visão fantasmagórica de New York, mas que pode ser perfeitamente projetado num outro cenário urbano ${ }^{49}$. Enquanto Roteiro para um filme tem um formato de roteiro cinematográfico, Roteiro Turístico de Goddamn City em nada se parece com um poema épico, tendo feições de guia turístico. Neste sentido, os dois textos de Sant'Anna elucidam a discussão em torno da temática dos gêneros literários, propondo sua dissolução.

Já em uma coletânea de mini-contos, publicadas no SLMG sob o título de Três pequenas estórias ${ }^{50}$, o experimentalismo de Sant'Anna opera por outros caminhos. Estes contos trabalham um enredo concatenado, mas o que se nota de experimental é o caráter de hiper-condensação dos textos.

$\mathrm{Na}$ narrativa 1, uma mulher, que vive debaixo da ponte junto com outros mendigos é acariciada por um homem que ali surge e, sem vontade ou forças para resistir, a mulher não o impede de concluir o intercurso sexual: "Ela nada obteve que se assemelhasse a um prazer, pois a única coisa para a qual estava apta a sentir, além da fome, era um tremendo cansaço" ${ }^{\prime 1}$. A narrativa 2 relata a noite de núpcias de um sargento de polícia, que percebe que sua mulher não era virgem, e a mata com 25 facadas, deixando, então, o lençol sujo de sangue. Na terceira narrativa, uma mulher desfere golpes contra a cabeça de seu marido, até a morte, com um ferro de passar, vingando-se das frequentes surras que dera em seus filhos e nela. Após sua morte, ela deixa o corpo morto na sala e vai ao quarto dos filhos para dar-lhes um beijo de boa noite. Nesses três relatos, o narrador preza por um enredo levado ao cúmulo do sintetismo em detrimento de divagações subjetivas e descrições espaciais (presentes em alguns de seus contos anteriores). Ainda, ele aborda o universo feminino, problematizando o machismo, a opressão feminina e a violência contra a mulher. Do corpus dos contos dos quatro autores publicados entre 1966 e 1975, este é o único que coloca em perspectiva tais questões.
51. SANT'ANNA, Três pequenas estórias.
EM TESE
BELO HORIZONTE
v. 19
N. 3
SET.-DEZ. 2013
MAROCA. Experimentalismo e liberdade no Suplemento Literário [...]
P. $77-93$

\section{Ensino e teoria}


52. GOUVÊA. Um relatório de viagem. Conto publicado no nû̉
53. GOUVÊA. Signos. Conto publicado no número 296 do SLMG, abr. 1972. Cf. GOUVÊA, 1972.

54. SANT'ANNA. Conto (não conto). Conto publicado no número 56. BAATHAAIXAB.2007, p.247-251.
Há, também, na obra de Jaime Prado Gouvêa uma vertente experimental, que consiste no abandono de um enredo ou um fio narrativo. No conto Um relatório de viagem $^{52}$, de 1971, tem-se a impressão de que o narrador é uma câmera cinematográfica que percorre, a descrever, os passageiros de um ônibus.

A maneira pela qual a narrativa se desenvolve, sem ações no tempo, e, sim, enfocando descrições espaciais, leva a uma ruptura com alguns preceitos da tradição do conto: não há eventos concatenados no enredo (e logo não há epílogo ou clímax); não há tampouco epifania ou integridade, na medida em que a fragmentação do texto, neste caso, não permite o desenvolvimento de ações. Assim, o espaço parece ser fixo e é o olhar que propicia a reflexão.

O conto $\operatorname{Signos}^{53}$, que não foi recolhido em livro posterior mente, compõe-se de recortes do horóscopo, dos signos de gêmeos e sagitário, dos dias 3 a 8 de abril, com as previsões para o trabalho, a saúde e o amor. Neste conto de caráter fragmentário, as ações não se desenvolvem e ficam suspensas como sugestão. A fragmentação é o próprio enredo.

O último texto de ficção, publicado por Sérgio Sant’Anna no penúltimo número de suplementos coordenados por Wander Piroli, é Conto (não conto) ${ }^{54}$, que se inicia com a seguinte reflexão:
Aqui, um território vazio, espaços, um pouco mais que nada Ou muito, não se sabe. Mas não há ninguém, é certo. Uma cobra, talvez, insinuando-se pelas pedras e pela pouca vegetação. Mas o que é uma cobra se não há nenhum homem por perto? Ela pode apenas cravar seus dentes numa folha, de onde escorre um líquido leitoso. Do alto desta folha, um inseto alça vôo, solta zumbidos, talvez de medo da cobra. Mas o que são os zumbidos se não há ninguém para escutá-los? São nada. Ou tudo. ${ }^{55}$

A partir da primeira frase: “Aqui, um território vazio, um pouco mais que nada”, já se coloca uma questão muito cara a este conto. O narrador dialoga com o leitor, propondo, claramente, um espaço no qual a narrativa poderá se desenvolver ou não, contanto que haja nele uma personagem. Não há histórias sem personagens assim como não há algo sem seu referente, que poderá variar e mudar. Assim, o narrador vai inserindo outros elementos à narrativa, jogando com possibilidades. Em síntese, ele sugere que ali, naquele espaço, onde colocara uma cobra, passe um homem com uma carroça e um cavalo, e que aquele cavalo seja picado pela cobra. Então, esse homem, após enterrar seu animal, prossegue puxando carroça até um espaço onde não mais interessa o que vai acontecer, já que, a partir dali, o limite espacial que havia sido limitado para esta narrativa seria extrapolado: "E, afinal, não podemos saber se o viram ou não, o homem puxando sua carroça, pois nos ocupamos apenas do que se passa aqui, neste espaço, onde nada se passa." ${ }^{56}$

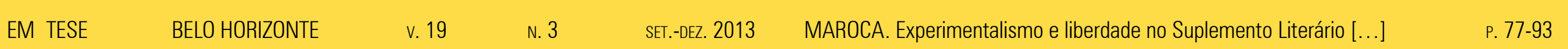

\section{Ensino e teoria}


Em seguida, o espaço é novamente tomado por homens, que chegaram para erguer postes. Estes, por sua vez, são roubados, e tudo volta a ser como antes: “às vezes, aqui é tão monótono que se imagina ver um vulto que se move por detrás dos arbustos" ${ }^{\prime 7}$. Sua imaginação prossegue a criar um menino ou um macaquinho que por ali passa; mas deve-se "respirar aliviado": esta personagem é de papel e tinta e não será mordida pela cobra. Esta personagem, assim como toda a narrativa, é construída no plano da possibilidade, fato que o narrador não permite que se esqueça:

Mas digam-me: se não há ninguém, como pode alguém contar esta estória? Mas isso não é uma estória, amigos. Não existe estória onde nada acontece. E uma coisa que não é uma estória talvez não precise de alguém para contá-la. Talvez ela se conte sozinha.

Mas contar o quê, se não há o que contar? Então está certo: se não há o que contar, não se conta. Ou então se conta o que não se há para contar. ${ }^{58}$

58. Ibidem, p.251.

Portanto, o texto apresenta fragmentos que anunciam uma possibilidade de enredo: a história do homem, que passa com seu cavalo e que poderá ser picado pela cobra. Estes fragmentos de contos se colocam como potencialidades criativas, geradoras de outras narrativas, mas, sobretudo, elucidam o caráter metalinguístico deste texto, que prima pela discussão da autorreferencialidade da narrativa em detrimento do desenvolvimento de seu enredo.
Ao se pensar na literatura dos novos, em especial a dos quatro escritores aqui destacados, nota-se que nem sempre foi possível constatar em seus textos o abandono dos aspectos de composição narrativa que caracterizam um conto, segundo contistas consagrados como Poe, Tchecov, Joyce.

O primeiro recorte de contos selecionados, que diz respeito à representação do sujeito, ora mostra um homem sufocado ora reificado. $\mathrm{O}$ trabalho com esta temática conduz à constatação de que o caráter de novidade que advém destes contos pode permitir a quebra com alguns aspectos do conto tradicional, como a abolição da intriga no enredo, do clímax ou da epifania, por exemplo. Mas, ainda que esses elementos não sejam suprimidos, o olhar que se tem do sujeito é, de certa forma, novo.

Não pretendo alegar que a literatura brasileira anterior a 1965 não se valha dos conflitos do homem. Grandes ficcionistas brasileiros recorreram a este aspecto, como Clarice Lispector, Guimarães Rosa, Graciliano Ramos, Machado de Assis, Cyro dos Anjos, apenas para citar alguns. Nos contos dos novos, há as descrições das sensações e pensamentos dos protagonistas, em detrimento de descrições espaciais, e a ênfase na solidão desse sujeito tolhido por seu meio. Esses aspectos, ao apontarem para uma localidade histórica, urbana e geográfica, os particulariza como novos contistas.

EM TESE BELO HORIZONTE $\quad$ V. $19 \quad$ N. $3 \quad$ SET.-DEz. $2013 \quad$ MAROCA. Experimentalismo e liberdade no Suplemento Literário [...] $\quad$ P. 77-93

\section{Ensino e teoria}


Se estes escritores não podiam ser livres sob as condições em que viviam, a fuga para a liberdade criativa, no sentido de romper com prescrições ou moldes da composição literária, foi decerto uma maneira, ainda que simbólica, de dar fim às amarras que os prendiam. Já que falar em liberdade em um país que vivia sob o signo da repressão era um feito impossível, esta questão é transferida para a representação. E é assim que os contos de caráter experimental vão deixando de lado a questão do sujeito passa-se a visar uma liberdade formal. Criar novas possibilidades para a narrativa curta acaba por deslocar a questão da referencialidade para o seio da própria literatura.

A narrativa se transfigura como espaço de resistência, logrando libertar-se das urdiduras do poder. Este momento político é um traço peculiar do continente, sendo possível somente àqueles que vivenciaram a experiência da ditadura a criação e a pertença a este movimento literário. Esta experiência toca a escrita destes autores no sentido de se fazer necessária uma reinvenção de uma nova estética, espaço de resistência. Creio eu que a tentativa de ruptura dos antigos paradigmas do conto foi a maneira encontrada pelos novo de dar vazão a este ímpeto de liberdade que lhes havia sido tolhida. Foi esta mesma busca pela autonomia do sujeito que acabou resultando na busca pela liberdade estética tal como propunham os novos.
ARAÚJO, Laís Corrêa de. Da teoria e da prática do conto. Minas Gerais. Belo Horizonte: Secretaria de Cultura de Minas Gerais. Suplemento Literário, 7 abr. 1979. p. 6.

ARAÚJJO, Laís Corrêa de. O Conto Mineiro: Anamnese e Diagnóstico. Minas Gerais. Belo Horizonte: Secretaria de Cultura de Minas Gerais. Suplemento Literário, n. 953, jan. 1985, p.3.

BOSI, Alfredo. História concisa da Literatura Brasileira. São Paulo: Cultrix, 2006

BOSI, Alfredo.
Cultrix, 1978.

BRASIL, Assis. A Nova Literatura III: O conto. Rio de Janeiro: Companhia Editora Americana/ MEC, 1975.

COELHO, Haydée Ribeiro. Diversidade crítica e literária no Suplemento Literário do Minas Gerais (1966-73): ruptura de fronteiras. In: O eixo e a roda. Belo Horizonte, 2003/2004, p. 85-96, n. 9/10.

COELHO, Haydée Ribeiro. O Suplemento Literário: 1969-1981. Suplemento. Secretaria de Estado de Cultura de Minas Gerais, Dez. 2006, p.6-9.

COELHO, Haydée Ribeiro. Suplemento Literário do Minas Gerais: apontamentos para uma história em processo. Suplemento. Secretaria de Estado de Cultura de Minas Gerais, Nov. 2005.

COUTINHO, Afrânio. A literatura no Brasil. Rio de Janeiro: Sul Americana, 1968.

\section{Ensino e teoria}


FREITAS FILHO, Armando; BUAROUE DE HOLLANDA, Heloísa ; GONÇALVES, Marcos Augusto. Anos 70: 2-Literatura. Rio de Janeiro: Europa, 1980.

GOMES, Duílio. Arquivo. Suplemento. Belo Horizonte: Secretaria de Cultura de Minas Gerais, n. 28, ago. 1997, p.12-13.

GOUVÊA, Jaime Prado. A noite grande. In: Areia tornando em pedra. Belo Horizonte: Oficina, 1970a. p. 15-23.

GOUVÊA, Jaime Prado. Círculos. Minas Gerais. Belo Horizonte: Secretaria de Cultura de Minas Gerais. Suplemento Literário, n 211, set. 1970, p. 8

GOUVÊA, Jaime Prado. Chuva. In: Areia tornando em pedra. Belo Horizonte: Oficina, 1970a. p.91-96.

GOUVÊA, Jaime Prado. O segundo degrau. In: Areia tornando em pedra. Belo Horizonte: Oficina, 1970a. p.97-104.

GOUVÊA, Jaime Prado. Os campos dourados. In: Areia tornando em pedra. Belo Horizonte: Oficina, 1970a. 105- 111.

GOUVÊA, Jaime Prado. Signos. Minas Gerais. Belo Horizonte: Secretaria de Cultura de Minas Gerais. Suplemento Literário, n 296, abr. 1972, p. 9

GOUVÊA, Jaime Prado. Um relatório de viagem. In:Fichas de vitrola e outros contos. Rio de Janeiro: Record, 2007. p.185-194.

GOTLIB, Nádia Battella. Teoria do conto. São Paulo: Ática, 2002. $10^{\mathrm{a}}$ ed., $4^{\mathrm{a}}$ reimp.
HOLLANDA, Heloísa Buarque de. Impressões de viagem: CPC vanguarda e desbunde: 1960/70. São Paulo, Brasiliense, 1980.

SANT'ANNA, Sérgio. A fábrica. In: Notas de Manfredo Rangel Repórter (A respeito de Kramer). Rio de Janeiro: Civilização Brasileira, 1973b. p.91-101

SANT'ANNA, Sérgio. A morte. Minas Gerais. Belo Horizonte: Secretaria de Cultura de Minas Gerais. Suplemento Literário, n. 156, ago. 1969b, p.5.

SANT'ANNA, Sérgio. A morte do pintor surrealista. Minas Gerais. Belo Horizonte: Secretaria de Cultura de Minas Gerais. Suplemento Literário, n. 259, ago. 1971. p.6-7.

SANT'ANNA, Sérgio. A morte do pintor surrealista. In: $\mathbf{5 0}$ contos e3 novelas de Sérgio Sant'Anna. São Paulo: Companhia das Letras, 2007. p.63-65.

SANT'ANNA, Sérgio. Conto (não conto). In: $\mathbf{5 0}$ contos e $\mathbf{3}$ novelas de Sérgio Sant'Anna. São Paulo: Companhia das Letras, 2007. p. $247-251$.

SANT'ANNA, Sérgio. Depoimento: o conto não existe. Minas Gerais. Belo Horizonte: Secretaria de Cultura de Minas Gerais. Suplemento Literário, n.357, jun.1973a, p. 6-7.

SANT'ANNA, Sérgio. Lassidão. In: O sobrevivente. Belo Horizonte: Minas Gráfica, 1969a. p. 51-55.

SANT'ANNA, Sérgio. O arquiteto. In: Notas de Manfredo Rangel Repórter (A respeito de Kramer). Rio de Janeiro: Civilização Brasileira, 1973b. p.143-149.

\section{Ensino e teoria}


SANT'ANNA, Sérgio. O automóvel. Minas Gerais. Belo Horizonte: Secretaria de Cultura de Minas Gerais. Suplemento Literário, n. 301, jun. 1972a, p. 6-7.

SANT'ANNA, Sérgio. O pelotão. In: Notas de Manfredo Rangel, Repórter (A respeito de Kramer). Rio de Janeiro: Civilização Brasileira, 1973b. p.51-56.

SANT'ANNA, Sérgio. $\mathbf{O}$ sobrevivente. Belo Horizonte: Minas Gráfica, 1969a.

SANT'ANNA, Sérgio. Obra aberta. Minas Gerais. Belo Horizonte: Secretaria de Cultura de Minas Gerais. Suplemento Literário, n. 316, set. 1972 b, p. 3.

SANT'ANNA, Sérgio. Os novos de Minas: o problema da participação. Minas Gerais. Belo Horizonte: Secretaria de Cultura de Minas Gerais. Suplemento Literário, n.84, fev. 1968a, p.3.

SANT'ANNA, Sérgio. Roteiro para um filme (video-tape) cultural. Minas Gerais. Belo Horizonte: Secretaria de Cultura de Minas Gerais. Suplemento Literário, n. 327, dez. 1972c, p. 6.

SANT'ANNA, Sérgio. Roteiro turístico de Goddamn-City. Minas Gerais. Belo Horizonte: Secretaria de Cultura de Minas Gerais. Suplemento Literário, n. 351, maio 1973c, p. 4-6.

SANT'ANNA, Sérgio. Três pequenas estórias. Minas Gerais. Belo Horizonte: Secretaria de Cultura de Minas Gerais. Suplemento Literário, n. 288, mar. 1972d, p. 9

SANTIAGO, Silviano. (supervisão) Glossário de Derrida. Rio de Janeiro: Francisco Alves, 1976
SANTIAGO, Silviano. Nas malhas da letra. Rio de Janeiro: Rocco, 2000

SANTIAGO, Silviano. Vale quanto pesa. Rio de Janeiro: Paz e Terra, 1982

SUPLEMENTO LITERÁRIO DO MINAS GERAIS. Secretaria de Cultura de Minas Gerais: Belo Horizonte, 3 set. 1966. Ano 1, n 1, p.1-12.

SÜSSEKIND, Flora. Literatura e vida literária. Polêmicas, diários \& retratos. Belo Horizonte: UFMG, 2004. $2^{\text {a }}$ edição.

VIEIRA, Luis Gonzaga. Aparte à literatura dos novos. Minas Gerais.Belo Horizonte: Secretaria de Cultura de Minas Gerais. Suplemento Literário, n. 74, jan. 1968, p.2.

VIEIRA, Luis Gonzaga. O conto atual. Minas Gerais. Belo Horizonte: Secretaria de Cultura de Minas Gerais. Suplemento Literário, n. 210, 5 set. 1970a, p. 10-11.

VIEIRA, Luis Gonzaga. O conto atual II. Minas Gerais. Belo Horizonte: Secretaria de Cultura de Minas Gerais. Suplemento Literário, n. 211, 12 set. 1970b, p. 10

VIEIRA, Luis Gonzaga. O conto atual III. Minas Gerais. Belo Horizonte: Secretaria de Cultura de Minas Gerais. Suplemento Literário, n. 212, 19 set. 1970c, p. 8.

VIEIRA, Luis Gonzaga. O conto atual IV. Minas Gerais. Belo Horizonte: Secretaria de Cultura de Minas Gerais. Suplemento Literário, n. 216, 17 out. 1970d, p. 8.

\section{Ensino e teoria}


VIEIRA, Luis Gonzaga. O conto atual V. Minas Gerais. Belo Horizonte: Secretaria de Cultura de Minas Gerais. Suplemento Literário, n. 217, 24 out. 1970e, p. 8.

VIEIRA, Luis Gonzaga. O conto atual VI. Minas Gerais. Belo Horizonte: Secretaria de Cultura de Minas Gerais. Suplemento Literário, n. 218, 31 out. 1970f, p. 8.

VIEIRA, Luis Gonzaga. Os novos de toda parte XXI: Lucienne Samôr: Os monstros e fantasmas de Lucienne Samôr. Minas Gerais. Belo Horizonte: Secretaria de Cultura de Minas Gerais. Suplemento Literário, n. 188, abr. 1970i, p. 8-9.

VIEIRA, Luis Gonzaga. Situação do Conto em Minas (trechos de um ensaio). Minas Gerais. Belo Horizonte: Secretaria de Cultura de Minas Gerais. Suplemento Literário, n. 191, 25 abr. 1970g, p. 9-10.

VIEIRA, Luis Gonzaga. Variaç̃es sobre o conto. Minas Gerais. Belo Horizonte: Secretaria de Cultura de Minas Gerais. Suplemento Literário, n. 189, 11 abr. 1970h, p. 7

VILELA, Luiz. Felicidade. Minas Gerais. Belo Horizonte: Secretaria de Cultura de Minas Gerais. Suplemento Literário, n. 106, set. 1968c, p. 21

VILELA, Luiz. Lavouras. In: No bar. Rio de Janeiro: Bloch, 1968a. p. 37-39.

VILELA, Luiz. Lembrança. Minas Gerais. Belo Horizonte:

Secretaria de Cultura de Minas Gerais. Suplemento Literário, n. 97, jul. 1968b, p. 1.

VILELA, Luiz. O suicida. In: Melhores contos. São Paulo: Global، 2001. $3^{a}$ edição. p.123-129.
VILELA, Luiz. Subir na vida. Minas Gerais. Belo Horizonte: Secretaria de Cultura de Minas Gerais. Suplemento Literário, $\mathrm{n}$ 212, set. 1970, p. 9.

VILELA, Luiz.Triste. In: Melhores contos. São Paulo: Global, 2001. $3^{\mathrm{a}}$ edição. p.55-61.

WERNECK, Humberto. Do terceiro andar. Minas Gerais. Belo Horizonte: Secretaria de Cultura de Minas Gerais. Suplemento Literário, n. 106, set. 1968a, p. 25.

WERNECK, Humberto. Febre aos trinta e nove degraus. Minas Gerais. Belo Horizonte: Secretaria de Cultura de Minas Gerais. Suplemento Literário, n. 74, jan. 1968b, p. 12.

WERNECK, Humberto. O condenado. Minas Gerais. Belo Horizonte: Secretaria de Cultura de Minas Gerais. Suplemento Literário, n. 49, ago. 1967, p. 5.

WERNECK, Humberto. O desatino da rapaziada: Jornalistas e escritores de Minas Gerais. São Paulo: Companhia das Letras, 1992.

WERNECK, Humberto. Quarta-feira. Minas Gerais. Belo Horizonte: Secretaria de Cultura de Minas Gerais. Suplemento Literário, n. 101, ago. 1968c, p.6.

EM TESE

BELO HORIZONTE

v. 19

N. 3

SET.-DEZ. 2013

\section{Ensino e teoria}

